\title{
Humble Foley's catheter to the rescue in a case of $\mathrm{T}$-tube insertion -a case report-
}

\author{
Upasana Goswami and Praneet Singh \\ Department of Anesthesia, Deen Dayal Upadhyay Hospital, Hari Nagar, New Delhi, India
}

The Montgomery T-tube poses a challenge to anesthesiologists because of loss of anesthetic gases through the open proximal end of the vertical limb and lack of standard anesthesia circuit connectors. Here, we present a case of a 25 -yearold woman with a reported history of accidental strangulation 18 months previously. The patient had a metallic tracheostomy tube in situ due to the development of tracheal stenosis. Computed tomography showed significant narrowing in a $7-8$-mm segment, $2 \mathrm{~cm}$ proximal to the tracheostomy tube in situ. She was scheduled for tracheal reconstruction surgery and T-tube insertion due to persistent subglottic stenosis. In this case, the Foley's catheter, which was inserted into the glottis orally, not only aided easy insertion of the T-tube into the trachea through the tracheal stoma, but also enabled us to stop the loss of anesthetic gases through the proximal vertical limb of the T-tube.

Key Words: Foley's catheter, Tracheal stenosis, T-tube.

The Montgomery T-tube was designed by William W. Montgomery in 1964 for prevention of postoperative tracheal stenosis in patients following reconstructive surgery on the cervical trachea [1]. This tube serves a dual purpose as a tracheal stent and airway conduit [2]. The vertical limb of the T-tube is intraluminal, whereas the horizontal limb is extraluminal, protruding through the tracheostomy orifice.

The Montgomery T-tube poses a particular challenge to the anesthesiologist during its surgical insertion, as well as when a patient with this type of tube in situ is scheduled for surgery. This is because of loss of anesthetic gases through the open

Corresponding author: Praneet Singh, M.D.

Department of Anesthesia, Deen Dayal Upadhyay Hospital, Hari Nagar, New Delhi 110064, India

Tel: 91-11-23978077, Fax: 91-11-23364689

Email: singhpraneet87@gmail.com

ORCID: https://orcid.org/0000-0003-0924-6392

Received: January 10, 2017.

Revised: February 11, 2017 (1st); February 24, 2017 (2nd).

Accepted: February 24, 2017.

Korean J Anesthesiol 2017 December 70(6): 648-651

https://doi.org/10.4097/kjae.2017.70.6.648 proximal end of the vertical limb and that T-tubes do not come with standard anesthesia circuit connectors. Various methods for management of the above problems have been described [3-6].

Here, we describe the management of a case of posttraumatic tracheal stenosis scheduled for tracheal reconstruction surgery and T-tube insertion, where a Foley's catheter was used to manage the problems of disagreement among standard anesthesia circuit connectors, leakage, and difficulty of T-tube guidance.

\section{Case Report}

A 25 -year-old woman weighing $40 \mathrm{~kg}$, with a reported history of accidental strangulation caused by a "dupatta" (scarf) caught in a factory machine presented to the emergency department with complaints of neck pain and breathing difficulties 18 months previously. The patient was intubated, kept on ventilator support in the intensive care unit, and then gradually weaned off the ventilator. Tracheostomy was performed on hospitalization day 10. A metallic tracheostomy tube was inserted and the patient was discharged and advised to attend regular follow-ups at the outpatient department. This time the patient was scheduled for tracheal reconstruction surgery due to persistent subglottic stenosis (Fig. 1). On preanesthetic examination, all blood pa-

(c) This is an open-access article distributed under the terms of the Creative Commons Attribution Non-Commercial License (http://creativecommons.org/ licenses/by-nc/4.0/), which permits unrestricted non-commercial use, distribution, and reproduction in any medium, provided the original work is properly cited. 

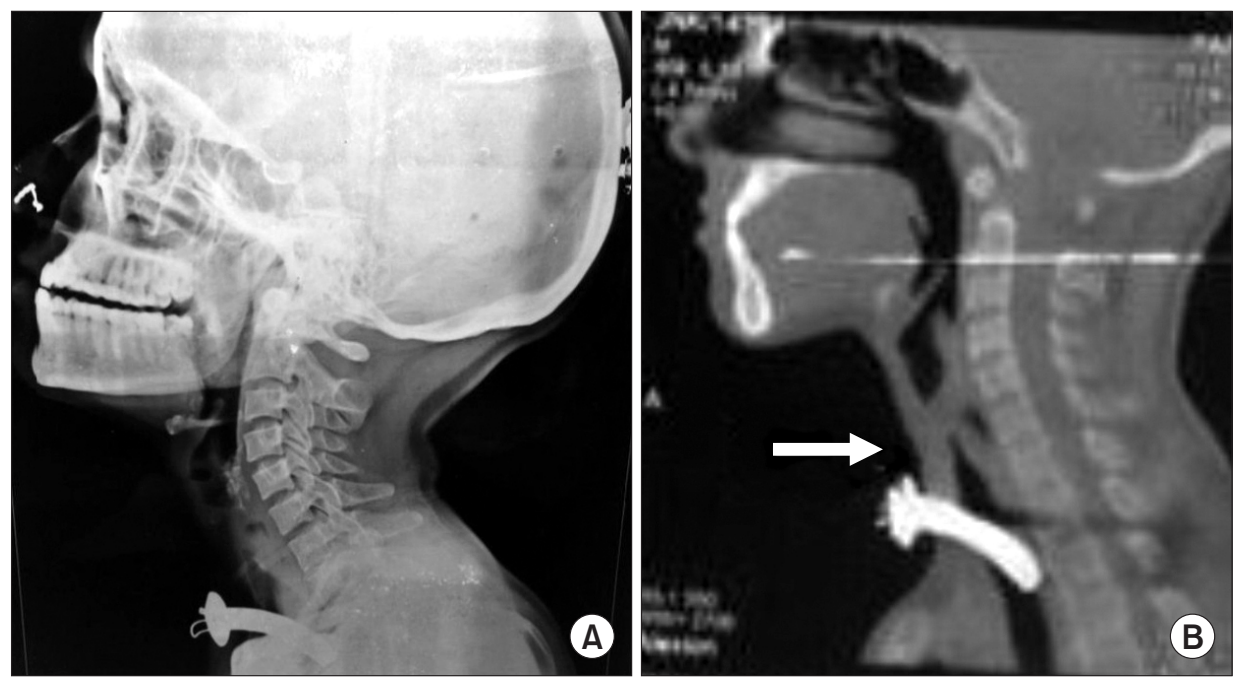

Fig. 1. (A) Lateral view X-ray of the neck and (B) non-contrast computed tomography (NCCT) scan showing subglottic stenosis.

rameters were within normal limits. A computed tomography scan of the thorax showed significant narrowing, with near-total occlusion of a small segment 7-8 $\mathrm{mm}$ in length and $2 \mathrm{~cm}$ proximal to the tracheostomy tube. Preoperative fiber optic laryngoscopic examination showed bilateral decreased mobility of the vocal cords and a subglottic stenotic area with granulation tissue over the tracheal side of the tracheostomy stoma.

The patient provided informed consent and was kept nil orally for 8 hours. Premedication with alprazolam $(0.25 \mathrm{mg})$, ranitidine $(150 \mathrm{mg})$, and metoclopramide $(10 \mathrm{mg})$ was performed orally on the night before, and the morning of, surgery. All drugs and equipment, including the difficult airway trolley, were kept ready in the operating room (OR). A pulse oximeter, non-invasive blood pressure monitor, electrocardiogram monitor, and end tidal $\mathrm{CO}_{2}$ monitor were employed in the OR. Preoperatively, the metallic tube was replaced with a cuffed PVC tracheostomy tube with an internal diameter (ID) of $7.0 \mathrm{~mm}$. The patient was premedicated with intravenous (i.v.) glycopyrrolate $(0.2 \mathrm{mg})$, fentanyl $(80 \mu \mathrm{g})$, and midazolam $(1 \mathrm{mg})$. Preoxygenation was performed with Bain's circuit attached to the tracheostomy port. The patient was induced with propofol (80 mg i.v.) and $2 \%$ sevoflurane to maintain the depth of anesthesia, followed by muscle relaxation with vecuronium ( $4 \mathrm{mg}$ i.v.). After induction, the tracheostomy tube was replaced with an armored cuffed endotracheal tube (ETT; $7.0 \mathrm{~mm}$ ID), and ventilation was continued. General anesthesia was maintained with oxygen, nitrous oxide, and sevoflurane, and supplemented with i.v. fentanyl and vecuronium as and when required. Fiberoptic visualization of the airway was performed to ascertain the level of the stenosed segment. The surgeons then proceeded with the planned surgery. The stenosed segment of the trachea was removed, followed by insertion of the T-tube $(12 \mathrm{~mm}$ external diameter [ED]), with tracheal reconstruction over it. A Foley's catheter (12 French) was inserted orally under laryngoscopic visualization with the aid of Magill's forceps (Fig. 2). The Foley's catheter was taken out through the tracheostomy site by the surgeon and then fitted into the proximal end of the vertical limb of the T-tube. The tip was adjusted such that it remained proximal to the junction of the vertical and horizontal segments of the T-tube to avoid hampering ventilation through the horizontal limb. The bulb of the Foley's catheter was then inflated with 5-6 cc of air (Fig. 2). The inflated Foley's bulb circumvented the problem of leakage of anesthesia gases into the atmosphere via the proximal end of the vertical limb of the Montgomery Ttube and also aided insertion of the T-tube into the trachea. The armored ETT inserted through the tracheostomy port was then removed, following which the distal portion of the vertical limb of the Montgomery T-tube was inserted and secured into place. Thereafter, Bain's circuit was connected to the horizontal extratracheal end of the T-tube using an ETT connector of a $7.5 \mathrm{~mm}$ ID ETT. The surgery then proceeded as planned with controlled ventilation through the T-tube. On completion of surgery, the neuromuscular blockade was reversed with neostigmine (2 mg) and glycopyrrolate $(0.4 \mathrm{mg})$ i.v., while $1 \%$ sevoflurane was continued. On the restoration of spontaneous respiration, and with the patient sedated, the Foley's catheter inserted per orally was deflated and removed. The patient was moved to the postoperative ward once awake.

\section{Discussion}

Insertion of the Montgomery T-tube poses a number of difficulties for the anesthetist, such as air dilution, hypoventilation, and awareness because of the open upper end of the tube $[5,6]$. Montgomery suggested passing a Fogarty embolectomy catheter through the extratracheal lumen up to the upper stem of the 

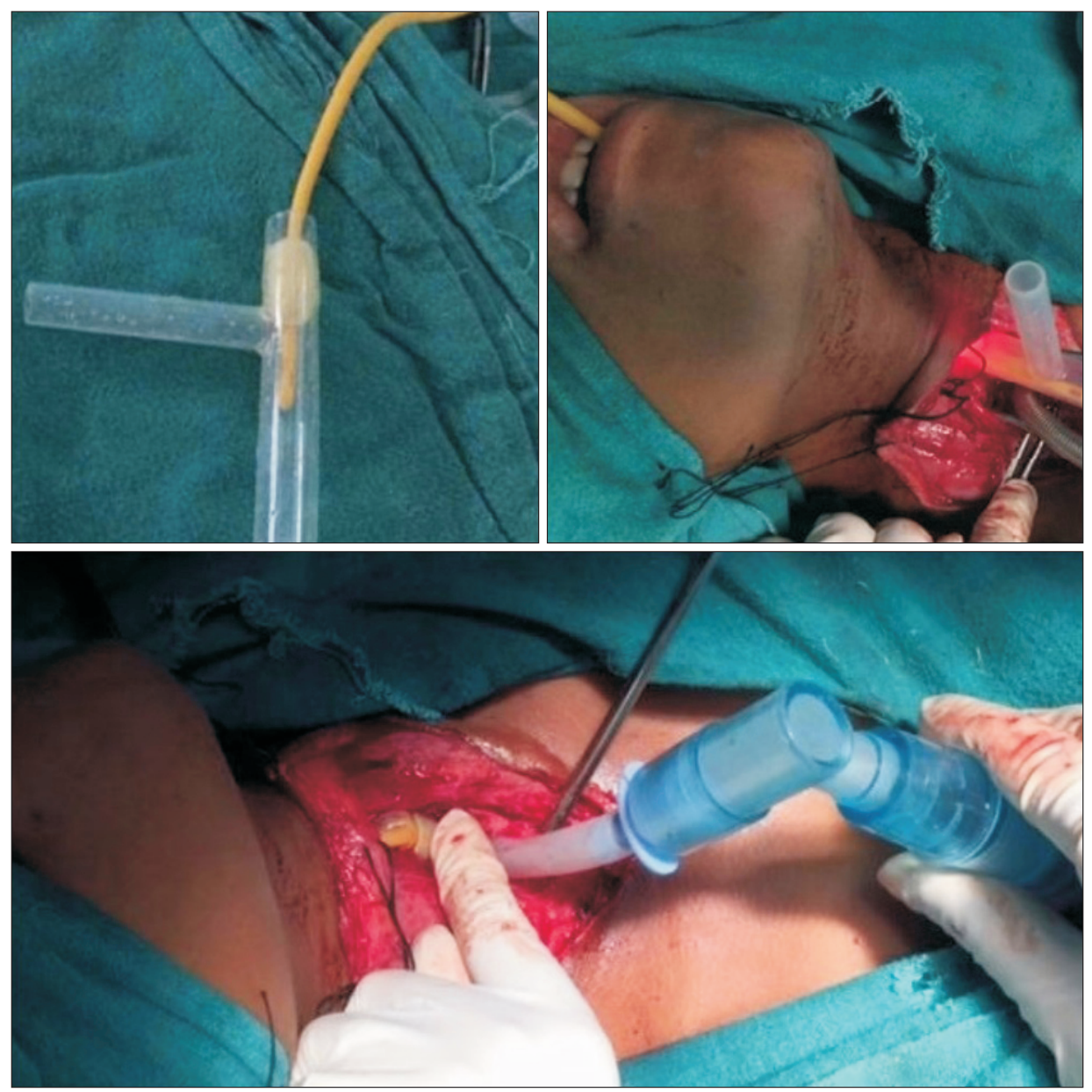

Fig. 2. Intraoperative images showing Foley's catheter and T-tube.

T-tube, and occluding the open upper end by inflating the balloon of the catheter. A suitably sized tracheal tube could then be placed in the extratracheal lumen of the T-tube adjacent to the catheter and ventilation continued [5]. A laryngeal mask airway and I-gel have been used by some authors to maintain ventilation [7]. The use of a Fogarty catheter for occlusion, and subsequent insertion of a smaller ETT, had the drawbacks of difficulty in directing the catheter upwards and increased resistance in ventilation.

Although many anesthesiologists prefer spontaneous respiration and total intravenous anesthesia for T-tube insertion $[3,6]$ patients with a T-tube in situ for another type of surgery pose a great problem. A case of emergency laparotomy, with acute intestinal obstruction and a high risk of aspiration, in which the T-tube could not be replaced by a cuffed tracheostomy tube, was managed by passing a Portex microlaryngeal tube ( $5 \mathrm{~mm} \mathrm{ID,} 7.3$ $\mathrm{mm} \mathrm{ED})$ through the entire T-tube in the tracheal lumen and inflating the cuff distal to the T-tube [8]. In our case too, spontaneous ventilation was not an option due to the nature of the surgery.
Joshi et al. [4] used a similar technique with a Foley's catheter and T-tube in a case of tracheoesophageal fistula with subglottic stenosis for ventilating the patient after T-tube insertion. Chonchubhair et al. [9] used a gum elastic bougie, which was inserted through a tracheal tube and taken out of the tracheal stoma, to insert the T-tube into the trachea. The Foley's catheter in our study not only helped with easy insertion of the T-tube into the trachea through the tracheal stoma, but also enabled us to stop the loss of anesthetic gases through the proximal vertical limb of the T-tube as the bulb could be inflated inside that limb. This definitely constituted a dual advantage of this simple device, which is available in any OR and can be used to manage cases of T-tube insertion.

\section{Acknowledgments}

Esteemed faculty members and technical staff members of the Department of Anesthesia, DDU Hospital, New Delhi, India. 


\section{References}

1. Montgomery WW. T-tube tracheal stent. Arch Otolaryngol 1965; 82: 320-1.

2. Wahidi MM, Ernst A. The Montgomery T-tube tracheal stent. Clin Chest Med 2003; 24: 437-43.

3. Kerai S, Gupta R, Wadhawan S, Bhadoria P. Anesthetic management of a patient with Montgomery t-tube in-situ for direct laryngoscopy. J Anaesthesiol Clin Pharmacol 2013; 29: 105-7.

4. Joshi S, Kulkarni A, Holkunde RS. A rare case of adult acquired tracheo-oesophageal fistula with sub-glottic stenosis for corrective surgeryan anesthetic challenge. J Clin Diagn Res 2014; 8: GD01-3.

5. Guha A, Mostafa SM, Kendall JB. The Montgomery T-tube: anaesthetic problems and solutions. Br J Anaesth 2001; 87: 787-90.

6. Kulkarni VR, Kelkar VS, Salunkhe SA. Anaesthetic challenges of the Montgomery T-tube insertion in a patient with fascioscapulohumeral dystrophy. Indian J Anaesth 2005; 49: 502-4.

7. Chung HS, Kim JY, Kwak JA, Park CS. Successful use of i-gel ${ }^{\mathrm{TM}}$ in a patient with tracheal stenosis undergoing Montgomery t-tube insertion. Korean J Anesthesiol 2013; 65(6 Suppl): S32-3.

8. Wouters KM, Byreddy R, Gleeson M, Morley AP. New approach to anaesthetizing a patient at risk of pulmonary aspiration with a Montgomery T-tube in situ. Br J Anaesth 2008; 101: 354-7.

9. Ní Chonchubhair A, O'Connor T, O'Hagan C. A novel approach to insertion of the Montgomery T-tube. Anaesthesia 1994; 49: 605-7. 